University of Nebraska - Lincoln

DigitalCommons@University of Nebraska - Lincoln

Faculty Publications: Department of Entomology

Entomology, Department of

2012

\title{
Nepetalactones from essential oil of Nepeta cataria represent a stable fly feeding and oviposition repellent
}

\author{
J. J. Zhu \\ U.S. Department of Agriculture (ARS-USDA), jerry.zhu@ars.usda.gov \\ Dennis R. Berkebile \\ University of Nebraska-Lincoln, DENNIS.BERKEBILE@ars.usda.gov \\ C. E. Dunlap \\ University of California - Santa Cruz, cdunlap@es.ucsc.edu
}

\author{
A. Zhang \\ ARS-USDA \\ D. Boxler \\ University of Nebraska-Lincoln, dboxler1@unl.edu
}

See next page for additional authors

Follow this and additional works at: https://digitalcommons.unl.edu/entomologyfacpub

Part of the Entomology Commons

Zhu, J. J.; Berkebile, Dennis R.; Dunlap, C. E.; Zhang, A.; Boxler, D.; Tangtrakulwanich, K.; Behle, R.; Baxendale, Frederick P.; and Brewer, Gary J., "Nepetalactones from essential oil of Nepeta cataria represent a stable fly feeding and oviposition repellent" (2012). Faculty Publications: Department of Entomology. 340.

https://digitalcommons.unl.edu/entomologyfacpub/340

This Article is brought to you for free and open access by the Entomology, Department of at DigitalCommons@University of Nebraska - Lincoln. It has been accepted for inclusion in Faculty Publications: Department of Entomology by an authorized administrator of DigitalCommons@University of Nebraska - Lincoln. 


\section{Authors}

J. J. Zhu, Dennis R. Berkebile, C. E. Dunlap, A. Zhang, D. Boxler, K. Tangtrakulwanich, R. Behle, Frederick P. Baxendale, and Gary J. Brewer 


\title{
Nepetalactones from essential oil of Nepeta cataria represent a stable fly feeding and oviposition repellent
}

\author{
J. J. Z H U ${ }^{1}$, D. R. B ER KE B I LE ${ }^{1}$, C. A. D UNL A P ${ }^{2}$, A. Z H A N G \\ D. B O XLER ${ }^{4}$, K. T A N G T R A K U L W A N I C H ${ }^{4}$, R. W. B E H L E \\ F. B A XENDA L E ${ }^{4}$ and G. BRE W E R \\ ${ }^{1}$ Agroecosystem Management Research Unit, Agricultural Research Service, U.S. Department of Agriculture (ARS-USDA), \\ Lincoln, NE, U.S.A., ${ }^{2}$ Crop Bioprotection Research Unit, ARS-USDA, National Center for Agricultural Utilization Research \\ Peoria, Peoria, IL, U.S.A., ${ }^{3}$ Invasive Insect Biocontrol and Behavior Laboratory, ARS-USDA, Beltsville Agricultural Research \\ Center-West Beltsville, Beltsville, MD, U.S.A. and ${ }^{4}$ Department of Entomology, University of Nebraska-Lincoln, Lincoln,
}

NE, U.S.A.

\begin{abstract}
The stable fly, Stomoxys calcitrans (L.) (Diptera: Muscidae), is one of the most serious pests to livestock. It feeds mainly on cattle and causes significant economic losses in the cattle industry. Standard stable fly control involving insecticides and sanitation is usually costly and often has limited effectiveness. As we continue to evaluate and develop safer fly control strategies, the present study reports on the effectiveness of catnip (Nepeta cataria L.) oil and its constituent compounds, nepetalactones, as stable fly repellents. The essential oil of catnip reduced the feeding of stable flies by $>96 \%$ in an in vitro bioassay system, compared with other sesquiterpene-rich plant oils (e.g. amyris and sandalwood). Catnip oil demonstrated strong repellency against stable flies relative to other chemicals for repelling biting insects, including isolongifolenone, 2-methylpiperidinyl-3-cyclohexen-1-carboxamide and (1S,2'S)-2-methylpiperidinyl-3-cyclohexen-1-carboxamide. The repellency against stable flies of the most commonly used mosquito repellent, DEET, was relatively low. In field trials, two formulations of catnip oil provided $>95 \%$ protection and were effective for up to $6 \mathrm{~h}$ when tested on cattle. Catnip oil also acted as a strong oviposition repellent and reduced gravid stable fly oviposition by $98 \%$.
\end{abstract}

Key words. Nepeta cataria, Stomoxys calcitrans, botanical-based repellent, oviposition repellent.

\section{Introduction}

The stable fly, Stomoxys calcitrans (L.), is one of the most problematic biting flies; it feeds mainly on bovids and equines in livestock barns, stables and pastures, and sometimes attacks pet animals and humans in cosmopolitan areas (Hafez \& Gamal-Eddin, 1959; Zumpt, 1973). Bunching, the defensive behaviour caused by stable fly attack on cattle, can result in reproductive failure and a reduction in meat and milk yields, with estimated economic losses of up to billions of dollars
(Campbell et al., 1977; Stork, 1979; Fraser \& Broom, 1990; D.B. Taylor, USDA-ARS, personal communication, 2011). Although the stable fly is not considered an important disease vector, it is capable of transmitting a variety of pathogens, including helminths, protozoans, bacteria and viruses, some of which are primary agents of mortality in cattle (Zumpt, 1973; Buxton et al., 1985; D'Amico et al., 1996).

The control of the stable fly includes methods such as insecticide applications and cultural control. The longterm use of toxic insecticides, however, is unsustainable and can lead

Correspondence: J. J. Zhu, Agroecosystem Management Research Unit, ARS-USDA, Lincoln, NE 68583, U.S.A. Tel.: 402 472 7525; Fax: 402 472 0516; E-mail: jerry.zhu@ars.usda.gov, mstrszhu@gmail.com 
to the development of insecticide resistance (Cilek \& Greene, 1994; Rozendaal, 1997). Furthermore, direct applications of insecticides to cattle provide only marginal control, especially for animals in pasture settings (Marcon et al., 1997; Campbell et al., 2001). Cultural practices involving the removal and dispersal of substrates can serve as a useful tool for reducing breeding sites, but are tedious and costly. Zumpt (1973) suggested that spraying cattle with repellents or applying contact insecticides to fly resting areas would suppress the development of stable fly infestation more effectively than direct insecticide application. Repellency might result from olfactory or contact stimulation that causes flies to avoid treated areas and substrates.

The use of repellents is considered as one of the most effective tools for protecting humans from biting insects (Curtis et al., 1991; Barnard, 2000; Isman, 2006). Recent studies have further demonstrated the effectiveness of botanicalbased repellents as alternatives against dipteran blood-sucking insects, particularly mosquitoes (Barnard, 1999; Sukumar et al., 1999; Schultz et al., 2004; Zhu et al., 2006). The use of repellents may represent an effective alternative strategy for reducing the impact of flies on livestock. Unfortunately, with the exception of certain insecticides that may also act as partial repellents, such as the organophosphates used in insecticideimpregnated ear tags (Liddel \& Clayton, 1982; Hogsette \& Ruff, 1986; Harris et al., 1987), few repellents have been made commercially available. However, the effectiveness of such ear tags for controlling stable flies is limited because the tags do not provide adequate coverage of the lower portions of the legs of cattle, on which stable flies commonly feed (Foil \& Hogsette, 1994). Furthermore, organophosphate-impregnated ear tags have very little effect on stable fly feeding. The tags were originally developed for horn fly control and stable flies may be less susceptible or may not remain on the host long enough to receive a toxic dose (Guglielmone et al., 2004). Not surprisingly, there is considerable interest in developing botanical repellents because of increasing regulation and negative public perception of synthetic insecticides (Coats, 1994; Isman, 2006). In addition, the U.S. Environmental Protection Agency (EPA) has ruled that many essential oils of plant origin are exempt from regulation under the Federal Insecticide, Fungicide, and Rodenticide Act of 1996. This shields these alternative repellent oils and compounds from prohibitive registration costs. The development of botanical repellent compounds would be a valuable tool in the integrated management of a range of biting flies that transmit livestock and human diseases. Zhu et al. $(2009,2010)$ reported that catnip oil at a dosage of $20 \mathrm{mg}$ effectively deterred the blood feeding of stable flies (>95\%) in a laboratory bioassay, and a wax-formulated catnip oil applied in stable fly resting areas was able to repel flies for up to $3 \mathrm{~h}$. Hieu et al. (2010) have further shown that essential oil of patchouli, Pogostemon cablin (Blanco) Bentham, can prevent stable flies from biting humans for up to $3.7 \mathrm{~h}$.

The present paper reports our findings on: (a) the feeding and oviposition repellency of the essential oil of catnip, Nepeta cataria L., including its major ingredient compounds $[(Z, E)$ nepetalactone and $(E, Z)$-nepetalactone], against stable flies; (b) comparisons of the effectiveness of the feeding repellency of catnip oil with those of previously identified biting insect repellents; (c) the effectiveness and longevity of catnip oil formulations that repel stable fly attack on cattle in the field, and (d) the effectiveness of catnip oil as an oviposition repellent against stable flies.

\section{Materials and methods}

\section{Repellent candidates}

Three plant essential oils were tested for feeding repellency of stable flies. Sandalwood oil (Santalum album) and amyris oil (Amyris balsamifera L.) were purchased from Olympian Labs, Inc. (Scottsdale, AZ, U.S.A.) and Sigma-Aldrich, Inc. (St Louis, MO, U.S.A.), respectively. Catnip essential oil was purchased from Bramble Berry, Inc. (Bellingham, WA, U.S.A.). The oil chemical composition was determined by gas chromatography-mass spectrometry (GC-MS) analysis based on methods described in Schultz et al. (2004) and Zhu et al. (2006), which showed it to comprise $(Z, E)$ - and $(E, Z)$-nepetalactone $(80 \%)$ and caryophyllene $(18 \%)$. The two nepetalactones were accumulated from the purchased catnip essential oil and purified ( $>95 \%)$ following the method described in Peterson (2001). $N, N$-diethyl-3-methylbenzamide (DEET) was purchased from Morflex, Inc. (Greensboro, NC, U.S.A.) with $>98 \%$ purity. (-)-Isolongifolenone (J4118) was prepared from (-)-isolongifolene purchased from Sigma-Aldrich, Inc. as described in Wang \& Zhang (2008) with $>98 \%$ purity. The 2-methylpiperidinyl-3-cyclohexen-1carboxamide (AI3-37220) was also purchased from Morflex, Inc. as a mixture of four diastereoisomers. Optically pure diastereoisomer (1S,2'S)-2-methylpiperidinyl-3-cyclohexen-1carboxamide (SS220) was purchased from Sai Dru Syn Laboratories Ltd (Hyderabad, India) (95\% stereoisomeric and $>99 \%$ chemical purity).

\section{Insects}

Stable flies used for laboratory bioassays were sourced from colonies maintained at the U.S. Department of Agriculture, Agricultural Research Service, Agroecosystem Management Research Unit (Lincoln, NE, U.S.A.). The flies were maintained at $23 \pm 2{ }^{\circ} \mathrm{C}$ at variable relative humidity $(\mathrm{RH})$ of $30-50 \%$ and an LD 12:12 h photoperiod. Adults were fed on citrated bovine blood $(3.7 \mathrm{~g}$ sodium citrate/L) in a bloodsoaked absorbent pad (Stayfree ${ }^{\circledR}$; McNeil-PPC, Inc., Skillman, NJ, U.S.A.) placed on top of a screened cage.

\section{Feeding repellency assay}

The laboratory bioassay for testing feeding repellency used six-well feeding reservoirs similar to the in vitro Klun and Debboun system described by Klun et al. (2005), but modified for stable fly use (Zhu et al., 2009). Newly emerged adult stable flies were supplied with $10 \%$ sugar water on day 1 . 
The sugar water was then removed and flies were fed with bovine blood once or twice. Adults (aged 2-3 days) were starved for $48 \mathrm{~h}$ prior to each test. The plant essential oils (20 mg) and synthetic catnip constituent compounds at three doses $(0.2 \mathrm{mg}, 2 \mathrm{mg}, 20 \mathrm{mg})$ were weighed out. Each of them was dissolved in $300 \mu \mathrm{L}$ of high-purity solvent (hexane) (Honeywell, Burdick \& Jackson, Inc., Muskegon, MI, U.S.A.) and then evenly applied to an outer layer cut from a sanitary pad $(4 \times 5 \mathrm{~cm})$. When the solvent had evaporated (after 2-3 min), the repellent-impregnated layer was placed on top of the blood-soaked sanitary pad in the reservoir well. Starved stable flies were transferred into each of the six testing cells (average of three to five flies in each cell). After $4 \mathrm{~h}$, surviving stable flies were anaesthetized with carbon dioxide $\left(\mathrm{CO}_{2}\right)$ and checked for feeding status by squashing their abdomen to determine the presence of blood. Flies in the repellent bioassay were exposed to randomized treatments (essential oil repellent candidates and various dosages of catnip oil) until at least six to eight replicates had been completed (new groups of flies were used for all replicated experiments). In tests of the feeding repellency of several newly identified synthetic insect antifeedants/repellents and DEET, dosages of $20 \mathrm{mg}$ were used and treatments were repeated at least five times.

\section{Oviposition repellency}

A total of three oviposition repellency experiments on the effects of catnip oil, its active constituent compounds and its spatial repellency on the oviposition of gravid female stable flies were conducted. A two-choice oviposition repellency assay was performed in a screen cage measuring $0.4 \times 0.4 \times 0.4 \mathrm{~m}$ with $\sim 400$ mixed-sex stable flies held in the laboratory at $23 \pm 2{ }^{\circ} \mathrm{C}$ and $30-50 \% \mathrm{RH}$. The stable flies were 10 days old and $>90 \%$ of the females were gravid (10 randomly selected females were dissected to determine the stage of ovarian development). These flies had not been previously provided with oviposition substrates. Oviposition jars were prepared by placing one end of a black cloth $(10 \times 30 \mathrm{~cm})$ in a small glass jar $(5.1 \mathrm{~cm}$ diameter, $7.6 \mathrm{~cm}$ high) filled with $\sim 200 \mathrm{~mL}$ of water to act as a wick. The middle portion of the cloth was draped over the mouth of the jar and fastened in place with a rubber band. The remaining end of the cloth was folded back to form a tunnel over the top of the jar for oviposition. Two oviposition jars were provided; the area of the black cloth forming the tunnel to one jar was treated with $100 \mathrm{mg}$ of catnip oil in $1 \mathrm{~mL}$ of hexane (treatment jar), whereas the cloth forming the tunnel to the other jar was treated with $1 \mathrm{~mL}$ of hexane only (control jar). The two jars were set in opposite corners $40 \mathrm{~cm}$ apart and their positions were alternated among replications to minimize possible position effects. After $6 \mathrm{~h}$, the jars were removed from the cage and eggs laid were rinsed from the black cloth with water into a plastic pan $(20 \times 10 \times 5 \mathrm{~cm})$. The eggs were transferred to a $10-\mathrm{mL}$ graduated cylinder and the number of eggs was estimated $(1 \mathrm{~mL} \approx 8000$ eggs). This bioassay was replicated 11 times.

In the second experiment, a total of four oviposition jars (four-choice test) were randomly placed $30 \mathrm{~cm}$ apart in the corners of the screen cage. The tunnel areas of three jars were treated with randomly selected repellent candidates $[100 \mathrm{mg}$ of catnip essential oil, $100 \mathrm{mg}$ of $(Z, E)$-nepetalactone, $100 \mathrm{mg}$ of $(E, Z)$-nepetalactone] in $1 \mathrm{~mL}$ of hexane topically applied to folded layers of the black cloth. The cloth (tunnel area) of the fourth jar was treated with $1 \mathrm{~mL}$ hexane as a control. The methods described above were used to measure the number of eggs laid in the various treatments. The experiments were replicated six times.

A third assay for spatial oviposition repellency was conducted within a large screen cage $(1.0 \times 0.5 \times 0.5 \mathrm{~m})$ inside a greenhouse at a temperature of $27 \pm 5{ }^{\circ} \mathrm{C}$ between 10.00 hours and 16.00 hours. Approximately 500 gravid female stable flies were released into the screened cage. Inside the cage, one catnip-treated oviposition jar and another untreated jar were placed $70 \mathrm{~cm}$ apart. Rather than topically applying repellent onto the tunnel area of the oviposition jar as in the previous experiments, we impregnated the upper one-third of four Whatman No. 1 filter papers (Whatman International Ltd, Maidstone, U.K.) used as a barrier with $100 \mathrm{mg}$ of catnip oil (in $1 \mathrm{~mL}$ hexane) so that the treated areas extended about $2 \mathrm{~cm}$ above the oviposition jar. The centred oviposition jar was placed at a distance of $2 \mathrm{~cm}$ from the repellent barrier. Experiment duration and egg counting methods were as described above. The experiments were repeated 10 times.

\section{Repellency of catnip oil formulations against stable flies in the field}

Two types of catnip formulation were prepared for evaluating catnip oil repellency in field trials. The oil-based formulation was prepared by adding $15 \%$ pure catnip essential oil (Bramble Berry, Inc.) to mineral oil (light oil form). For the water-based formulation, Triton X-100 (Sigma-Aldrich, Inc.) was used as a surfactant. This allowed the catnip oil to disperse in the water with minor agitation and remain in emulsion. The catnip water-based formulation contained 30\% catnip oil, $67 \%$ water and $3 \%$ Triton X-100.

The repellency against stable flies of two catnip formulations was tested on heifers and steers under field conditions during the summers of 2009 and 2010. The repellency tests were carried out in Lincoln/Mead (Agricultural Research and Development Center) and North Platte (University of Nebraska, West Central Research and Extension Center), Nebraska. Tests were conducted using criteria specified by the American Society for Testing and Materials (ASTM, 1980) and protocols approved by the Institutional Animal Care and Use Committee of the University of Nebraska (IACUC protocol no. 06-12-053C). To test the effectiveness of the catnip oil-based formulation, one front and one rear leg (randomly selected) were treated with $15 \%$ catnip oil $(\sim 25 \mathrm{~mL}$ of repellent formulation was applied per animal leg) using a bath sponge (Walmart, Inc.) soaked in formulation. The remaining two legs were similarly treated with mineral oil only as a control. The number of stable flies on each leg was visually counted hourly between 10.00 hours and 18.00 hours. These counts 

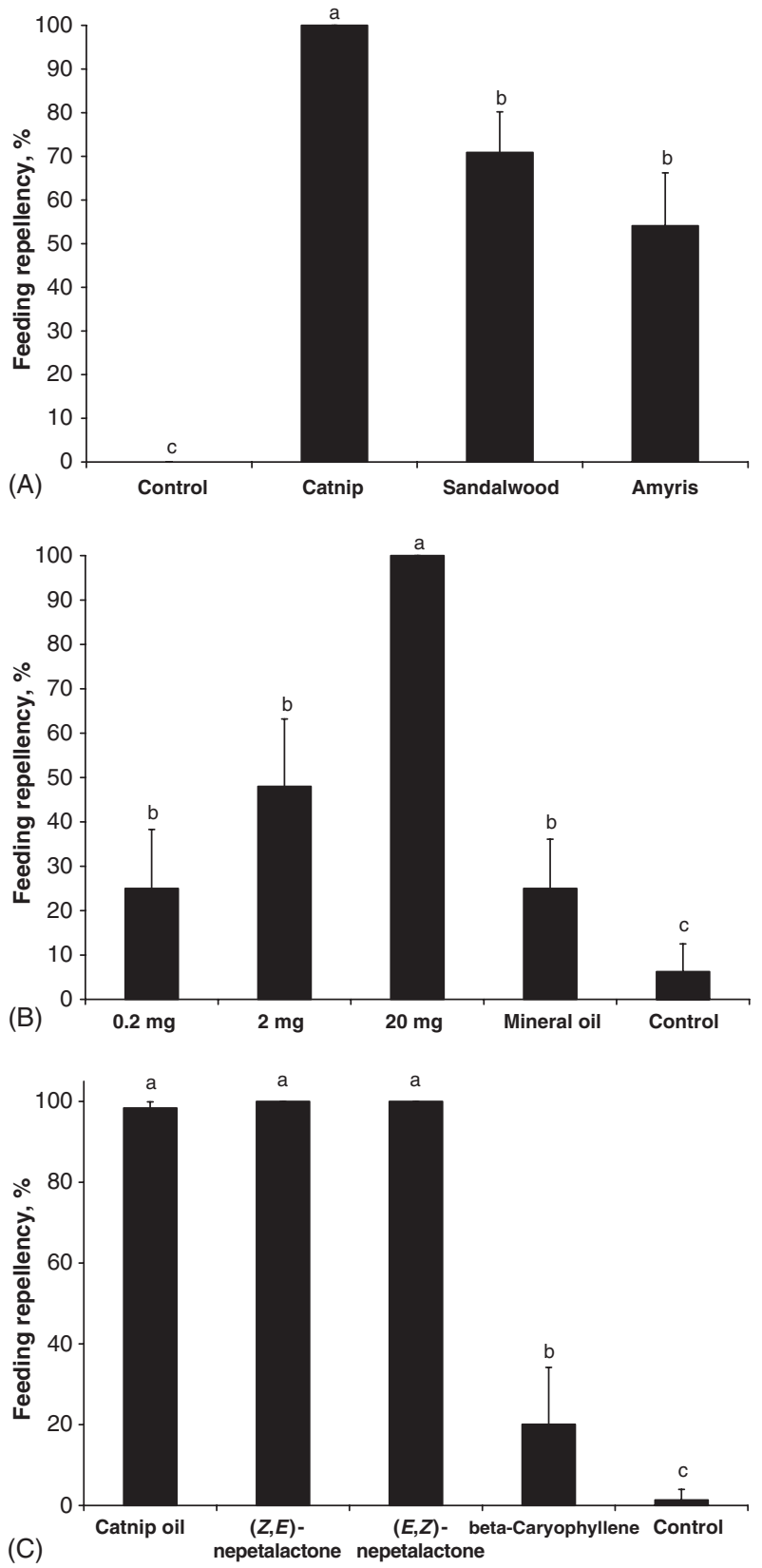

Fig. 1. Percentage feeding repellency of starved stable flies exposed to essential oils and their components in a laboratory in vitro system. (A) Plant essential oils and control treatments $(n=8)$. (B) Different dosages of catnip oil and control treatments $(n=6-8)$. (C) Catnip oil and its major compounds (all $20 \mathrm{mg})(n=8)$. Means with different letters differ significantly at $P<0.05$, ANOva followed by Duncan's test (A, C) and Student-Newman-Keuls test (B). Error bars show standard errors of the mean.

were confirmed using Microsoft Image Viewer to examine photographs taken during the observations. These tests were repeated three times, using five animals in each test. At least 2 weeks elapsed between tests to ensure that no residue of repellents applied in prior experiments remained.
For applications of the water-based catnip formulation, we used a compressed-air hand gun (J. E. Adams Industries Ltd, Cedar Rapids, IA, U.S.A.) powered with air pressure at $241 \mathrm{KPa}$. The test cattle $(n=4)$ were restrained in a cattle chute and a total of $250 \mathrm{~mL}$ of water-based catnip formulation was evenly sprayed on all four legs and the lower body of each animal. Control cattle $(n=4)$ were treated with the same volume of formulation, but only mineral oil had been added (30\% of total volume). Catnip-treated cattle were placed in pens situated at least $50 \mathrm{~m}$ downwind of the pens containing control animals. Fly densities on both treatment and control cattle were observed to be similar (10-15 flies per leg) before the tests. The method used to count stable flies on each animal was similar to those described for oil formulations. Observations were made hourly for a total of $6 \mathrm{~h}$ (12.00-18.00 hours) and again at $24 \mathrm{~h}$ after application.

\section{Statistical analysis}

Percentiles of feeding repellency [(number of flies feeding on control cattle - number of flies feeding on treated cattle)/number of flies feeding on control cattle $\times 100$ ] were determined and transformed to arcsine square-root values for analyses of variance (ANOVA) using IBM sPSS Statistics 18 (SPSS, Inc., Chicago, IL, U.S.A.). Significant differences at $P=0.05$ among percentage means were determined using Duncan's test (when the number of replicates per treatment were equal) and the Student-Newman-Keuls test (when these numbers were not equal). Repellencies are reported before arcsine transformation.

The number of eggs laid in the four-choice assay was subjected to ANOVA and the treatment means were separated using Duncan's multiple range test, with $\alpha=0.05$. Student's $t$-test was used to compare differences in egg counts in the two-choice and the spatial oviposition repellency assays.

Comparisons between treated and control animals of numbers of flies observed were performed using repeated-measures ANOvA. Results with $P$-values of $<0.05$ were considered statistically significant.

\section{Results}

\section{Stable fly feeding repellency assay}

The feeding repellencies of three essential oils (catnip, sandalwood, amyris) were evaluated using a laboratory bioassay newly developed for biting flies. Catnip oil strongly repelled stable flies from blood feeding with a repellency rate of $98 \%$, which was significantly higher than those of the other plant essential oils tested $(F=30.16$, d.f. $=3,28, P<0.05)$ (Fig. 1A). Over $98 \%$ of control flies were observed to be bloodfed. An additional dose-response test of catnip oil revealed that the highest dosage of $20 \mathrm{mg}$ provided better protection than the two lower doses tested $(F=12.01$, d.f. $=4,32, P<0.05)$ (Fig. 1B). By itself, mineral oil (light viscosity) was also found to deter feeding $(\sim 30 \%)$ at a rate comparable with that of the lowest concentration of catnip oil $(0.2 \mathrm{mg})$. The $(Z, E)$ - and $(E, Z)$-nepetalactones prevented stable flies from 
blood feeding as effectively as catnip essential oil ( $F=57.15$, d.f. $=4,35, P<0.05$ ) (Fig. 1C). Significantly lower repellency $(<20 \%)$ was observed for caryophyllene. We further compared catnip oil with several recently identified deterrents and repellents for repellency against blood-feeding arthropods. Substances tested included (-)-isolongifolenone (J4-118), 2-methylpiperidinyl-3-cyclohexen-1-carboxamide (AI3-37220) and (1S,2'S)-2-methylpiperidinyl-3-cyclohexen-1-carboxamide (SS220), as well as the most commonly used mosquito repellent, $N, N$-diethyl-3-methylbenzamide (DEET) (Klun et al., 2003, 2004; Zhang et al., 2009). The repellencies of catnip oil and AI3-37220 were significantly higher than that of DEET ( $F=11.41$, d.f. $=5,35, P<0.05)$ (Fig. 2). No differences were observed among DEET, J4-118 and SS220 in preventing stable fly feeding.

\section{Oviposition repellency of catnip oil}

When gravid female stable flies were given a choice of oviposition site, they laid approximately 20000 eggs on the control site and $\sim 100$ eggs on the catnip-treated oviposition medium (Fig. 3A) $(t=2.18, \quad P<0.05)$. The oviposition repellency of catnip was $97.26 \pm 0.79 \%$. A further four-choice oviposition experiment to compare the repellency of catnip oil with that of its major constituent compounds (nepetalactones) revealed that significantly more eggs were laid in the control jars $(F=83.36$, d.f. $=3,16, P<0.05)$, but no differences were found in numbers laid in the catnip- and nepetalactonetreated jars (Fig. 3B). We also observed that female stable flies laid fewer eggs in oviposition jars surrounded by the catnip oil-treated barrier, suggesting that catnip oil may act as an olfactory spatial repellent. Results of the oviposition repellency experiment using the catnip-treated barrier that surrounded but was not directly applied to the oviposition medium showed that gravid females laid $<100$ eggs in catnip-treated jars, whereas 14345 eggs were found in the control jars $(t=2.26$,

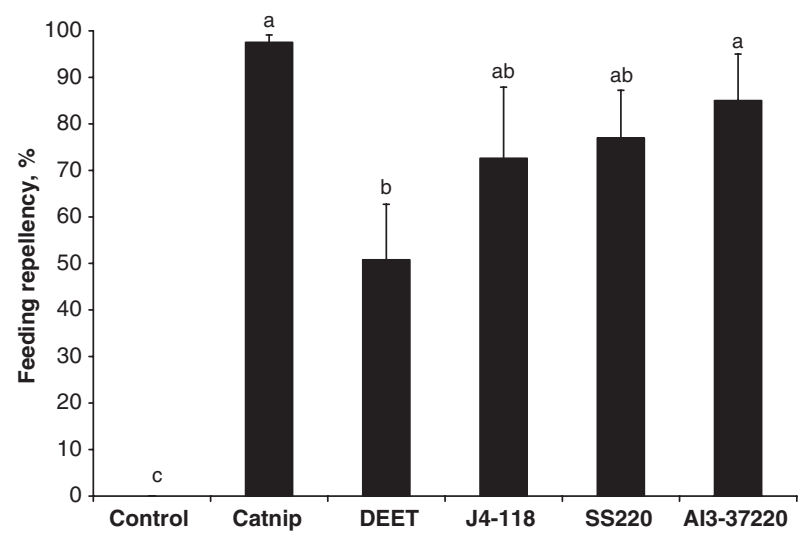

Fig. 2. Comparison of percentage feeding repellency of starved stable flies exposed to $20 \mathrm{mg}$ of catnip oil and other insect repellents in a laboratory in vitro system $(n=5-8)$. Means with different letters above bars differ significantly $(P<0.05$, ANOva followed by Student-Newman-Keuls test). Error bars show standard errors of the mean.
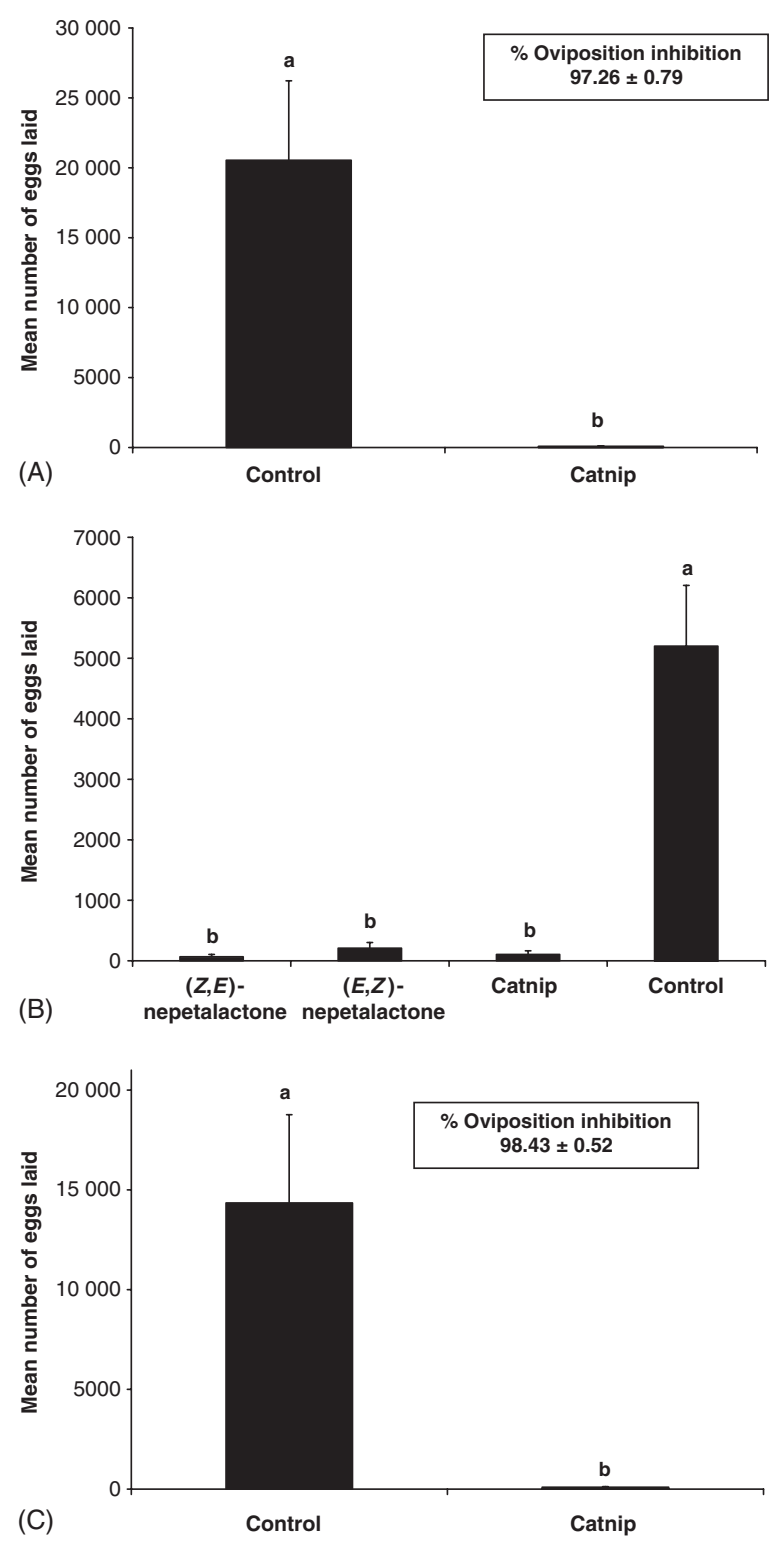

Fig. 3. Number of stable fly eggs deposited in (A) oviposition jars treated with $100 \mathrm{mg}$ of catnip oil or control $(n=11)$, (B) oviposition jars treated with $100 \mathrm{mg}$ of catnip oil, two catnip oil major components or control $(n=5)$ and (C) oviposition jars with and without a catnip oil-treated barrier $(n=10)$. Means with different letters above the bars differ significantly at $P<0.05$, Student's $t$-test $(\mathrm{A}, \mathrm{C})$ and ANova followed by Duncan's test (B). Control treatment comprised $100 \mathrm{mg}$ of solvent (hexane) used as carrier for the essential oils tested. Error bars show standard errors of the mean.

$P<0.05$ ) (Fig. 3C). The spatial oviposition repellency of catnip was estimated at $98.43 \pm 0.52 \%$.

\section{Field repellency test}

Numbers of stable flies on cattle legs treated with the $15 \%$ catnip oil-based formulation were significantly lower than 


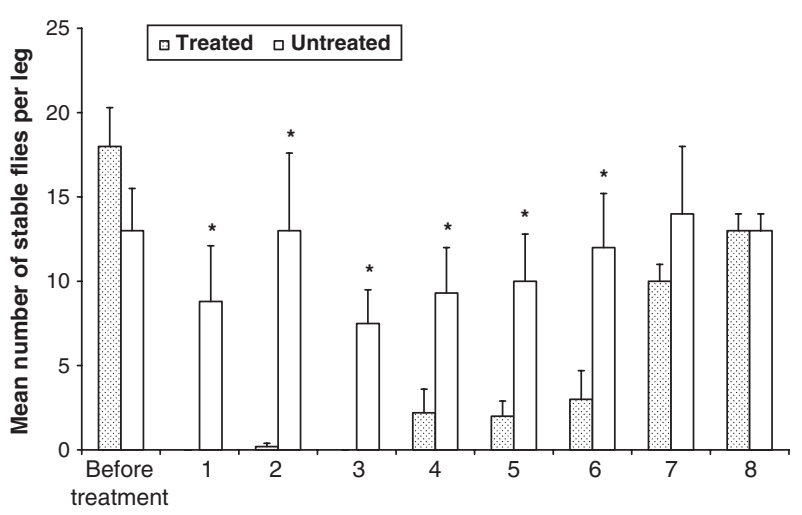

(A)

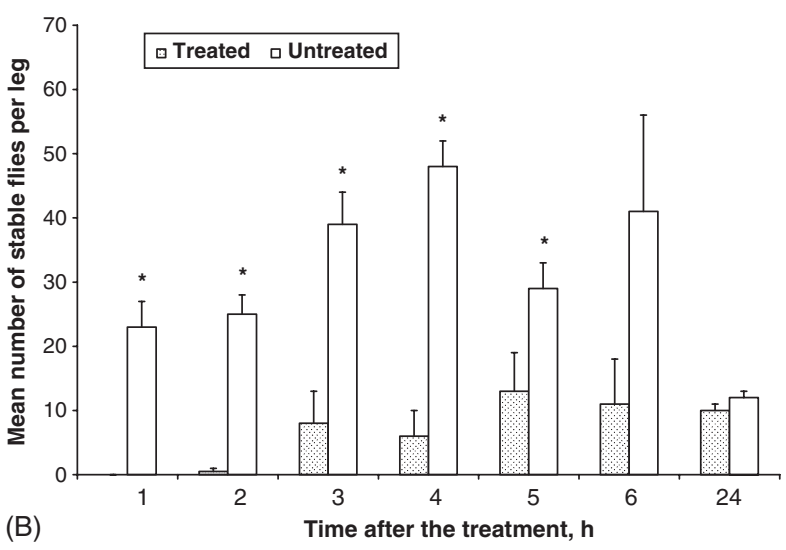

Fig. 4. Time-course of adult stable flies landing on legs of cattle treated with (A) $15 \%$ catnip oil in an oil-based formulation or control treatment and (B) 30\% catnip oil in a water-based formulation or control treatment. Means with an asterisk above a pair of bars by time after treatment differ significantly at $P<0.05$, Student's $t$-test. Error bars show standard errors of the mean.

those on untreated legs (Fig. 4A). Effective repellency (>90\%) lasted up to $6 \mathrm{~h}$ after application $(P<0.05)$ and disappeared in the seventh hour after application. Effective repellency $(>90 \%)$ of the water-based catnip formulation (30\%) was observed for only $4-5 \mathrm{~h}$ after application $(P<0.05)$ (Fig. 4B).

\section{Discussion}

Catnip has been reported as a potential alternative insect repellent, for which repellency against several disease-transmitting urban insect pests, including mosquitoes and cockroaches, has been documented (Peterson, 2001; Schultz et al., 2004; Bernier et al., 2005; Zhu et al., 2006). As a folk remedy, catnip has also been reported to repel up to 13 families of insects (Eisner, 1964). Catnip has very low acute oral, dermal and inhalation mammalian toxicities, levels of which are similar to those of other EPA-approved mosquito repellents (Zhu et al., 2009). The current study shows catnip oil to be a relatively strong feeding and oviposition repellent against stable flies. Our observations in laboratory spatial oviposition assays and field animal tests further suggest that catnip also serves as a spatial repellent to stable flies. This is the first study to demonstrate that catnip oil can inhibit gravid stable fly egg-laying behaviour (98\% inhibition). Therefore, it may be developed to control stable fly oviposition and, together with other effective means (such as the push-pull strategy), to further reduce populations of this pest in the field.

Sesquiterpene-rich amyris and sandalwood plant essential oils are known to provide significant repellency against various arthropod species, particularly against several mosquito species (Paluch et al., 2009). In comparison with catnip oil, their repellency against stable fly biting is relatively low. Similarly, the most common personal protectant against biting insects, DEET, was not found to be a strong repellent against stable flies (repellency rate: 50\%). Schreck et al. (1978) reported that DEET applied at a dose of $250 \mathrm{mg}$ on the forearm deterred stable fly biting for only 2-3 h. (-)-Isolongifolenone, 2-methylpiperidinyl-3cyclohexen-1-carboxamide and (1S,2'S)-2-methylpiperidinyl3-cyclohexen-1-carboxamide are three recently identified repellents against mosquitoes and ticks (Klun et al., 2001, 2003, 2004; Zhang et al., 2009). The levels of repellency of these compounds against stable flies were similar to that provided by catnip oil.

Catnip oil has been reported as an effective contact repellent against several mosquito species, but its repellency varies with dose and species (Bernier et al., 2005). Our study suggests that catnip oil must be administered at a dosage of $\geq 20 \mathrm{mg}$ $\left(1 \mathrm{mg} / \mathrm{cm}^{2}\right)$ to provide effective repellency (>90\%) against stable flies. Thus, using catnip oil as a topical repellent may be costly. From our observations in feeding and oviposition repellency assays in the laboratory and in cattle in the field condition, we noted that stable flies avoid the catniptreated substrates and hosts by abruptly flying away $(2-3 \mathrm{~cm}$ from catnip-treated targets). Our indoor behavioural assay conducted in a single caged olfactormeter further suggests that catnip oil may act as a spatial repellent (Zhu et al., 2010). Electroantennogram (EAG) trials of stable fly antennae exposed to catnip volatiles also elicited a significant response (Zhu et al., 2010), with a unique EAG pattern of both positive and negative peaks. Similar EAG responses in other insects may reflect the electrophysiological nature of insect response to repellent compounds (Contreras et al., 1989; Pavis \& Renou, 1990; Jyothi et al., 2008).

Most insect repellents operate in the vapour phase, in which volatiles can be detected by insect olfactory sensilla and are then kept at a distance (Garson \& Winnike, 1968). Repellents with high vapour pressure, such as catnip oil, may offer protection at low concentrations, but this carries a risk for the loss of repellency within a short time. This was confirmed in our field repellent trials, in which both formulations of catnip oil provided only about $5-6 \mathrm{~h}$ of protection. The longevity of a repellent formulation may not relate to its concentration, but, rather, to the physical and chemical properties of the repellent compound. This is supported by the fact that the $30 \%$ water-based formulation resulted in shorter effective time than the $15 \%$ oil-based formulation. More work is necessary to discover and develop more efficient formulations of plant essential oils in order to extend their longevity as repellents in general. 
In conclusion, catnip oil and its major constituent compounds, nepetalactones, act not only as effective feeding and oviposition repellents, but also have a strong spatial repellency. The in vitro blood-feeding assay has proven a useful screening tool for discovering novel repellents for stable flies. Field trials conducted on cattle of two catnip oil formulations found these gave 5-6 h of protection against stable flies. Formulating catnip oil to meet USDA organic standards may also have promise as a method for stable fly control in organic dairy farms (Isman, 2006, 2008).

\section{Acknowledgements}

We express our deep gratitude to B. Voelker and T. Weinhold (USDA-ARS, AMRU, Lincoln, NE, U.S.A.) for their technical help with this study. This work was conducted in cooperation with the Institute of Agriculture and Natural Resources, University of Nebraska-Lincoln, and supported partly by Regional Project 1030.

This paper reports the results of research only. Mention of a proprietary product does not constitute an endorsement or a recommendation for its use by the U.S. Department of Agriculture.

\section{References}

Barnard, D.R. (1999) Repellency of essential oils to mosquitoes (Diptera: Culicidae). Journal of Medical Entomology, 36, 625-629.

Barnard, D.R. (2000) Repellents and toxicants for personal protection: a WHO Position Paper. World Health Organization, Geneva.

Bernier, U.R., Furman, K.D., Kline, D.L.S., Allan, A. \& Barnard, D. (2005) Comparison of contact and spatial repellency of catnip oil and N,N-diethyl-3-methylbenzamide (DEET) against mosquitoes. Journal of Medical Entomology, 42, 306-311.

Buxton, B.A., Hinkle, N.C. \& Schultz, R.D. (1985) Role of insects in the transmission of bovine leukosis virus: potential for transmission by stable flies, horn flies, and tabanids. American Journal of Veterinary Research, 46, 123-126.

Campbell, J.B., White, R.G., Wright, J., Crookshank, E.R. \& Clanton, D.C. (1977) Effects of stable flies on weight gains and feed efficiency of calves on growing or finishing rations. Journal of Economic Entomology, 70, 592-594.

Campbell, J.B., Skoda, S.R., Berkebile, D.R., Boxler, D.J., Thomas, G.D., Adams, D.C. \& Davis, R. (2001) Effects of stable flies (Diptera: Muscidae) on weight gains of grazing yearling cattle. Journal of Economic Entomology, 94, 780-783.

Cilek, J.E. \& Greene, G.L. (1994) Stable fly (Diptera: Muscidae) insecticide resistance in Kansas cattle feedlots. Journal of Economic Entomology, 87, 275-279.

Coats, J.R. (1994) Risks from natural versus synthetic insecticides. Annual Review of Entomology, 39, 489-515.

Contreras, M., Perez, L.D. \& Rozas, R. (1989) Empirical correlations between electroantennograms and bioassays for Periplanata americana. Journal of Chemical Ecology, 15, 2539-2548.

Curtis, C.F., Lines, J.D., Baolin, L. \& Renz, A. (1991) Natural and synthetic repellents. Control of Disease Vectors in the Community (ed. by C. F. Curtis), pp. 75-92. Wolfe Publishing, London.
D’Amico, F., Gouteux, J.P., Le Gall, F. \& Cuisance, D. (1996) Are stable flies (Diptera: Stomoxyinae) vectors of Trypanosoma vivax in the Central African Republic? Veterinary Research, 27, 161-170.

Eisner, T. (1964) Catnip: its raison d'être. Science, 146, 1318-1320.

Foil, L.D. \& Hogsette, J.A. (1994) Biology and control of tabanids, stable flies and horn flies. Revue Scientifique et Tecnique, Office International des Epizootics, 13, 1125-1158.

Fraser, A.F. \& Broom, D.M. (1990) Farm Animal Behaviour and Welfare. Bailliere Tindall, London.

Garson, L.R. \& Winnike, M.E. (1968) Relationships between insect repellency and chemical and physical parameters-a review. Journal of Medical Entomology, 5, 339-352.

Guglielmone, A.A., Volpogni, M.M., Quaino, O.R., Anziani, O.S. \& Mangold, A.J. (2004) Abundance of stable flies on heifers treated for control of horn flies with organophosphate-impregnated ear tags. Medical and Veterinary Entomology, 18, 10-13.

Hafez, M. \& Gamal-Eddin, F.M. (1959) Ecological studies on Stomoxys calcitrans L. and sitiens Rond. in Egypt, with suggestions on their control (Diptera: Muscidae). Bulletin of the Entomological Society of Egypt, 43, 245-283.

Harris, J.A., Hillerton, J.E. \& Morant, S.V. (1987) Effect on milk production of controlling muscid flies, and reducing fly-avoidance behaviour, by the use of fenvalerate ear tags during the dry periods. Journal of Dairy Research, 54, 165-171.

Hieu, T.T., Kim, S.-I., Lee, S.-G. \& Ahn, Y.-J. (2010) Repellency to Stomoxys calcitrans (Diptera: Muscidae) of plant essential oils alone or in combination with Calophyllum inophyllum nut oil. Journal of Medical Entomology, 47, 575-580.

Hogsette, J.A. \& Ruff, J.P. (1986) Control of stable flies and horn flies (Diptera: Muscidae) with permethrin tapes applied to tails of beef and dairy cattle. Journal of Economic Entomology, 80, 417-420.

Isman, M.B. (2006) Botanical insecticides, deterrents, and repellents in modern agriculture and an increasingly regulated world. Annual Review of Entomology, 51, 45-66.

Isman, M.B. (2008) Botanical insecticides: for richer, for poorer. Pest Management Science, 64, 8-11.

Jyothi, K.N., Prasuna, A.L., Prasad, A.R. \& Yadav, J.S. (2008) Electrophysiological responses of both sexes of ground nut leaf miner, Aproaerema modicella (Lepidoptera: Gelechiidae) to synthetic female sex pheromone blend. Current Science, 94, 629-633.

Klun, J.A., Schmidt, W.F. \& Debboun, M. (2001) Stereochemical effects in an insect repellent. Journal of Medical Entomology, 38, 809-812.

Klun, J.A., Khrimian, A., Margaryan, A., Kramer, M. \& Debboun, M. (2003) Synthesis and repellent efficacy of a new chiral piperidine analogue: comparison with DEET and bay repel activity in humanvolunteer laboratory assays against Aedes aegypti and Anopheles stephensi. Journal of Medical Entomology, 40, 293-299.

Klun, J.A., Strickman, D., Rowton, E., Williams, J., Kramer, M., Robert, D. \& Debboun, M. (2004) Comparative resistance of Anopheles albimanus and Aedes aegypti to N,N-diethyl-3-methylbenzamide (DEET) and 2-methylpiperidinyl-3-cyclohexen-1-carboxamide (AI3-37220) in laboratory human-volunteer repellent assays. Journal of Medical Entomology, 41, 418-422.

Klun, J.A., Kramer, M. \& Debboun, M. (2005) A new in vitro bioassay system for discovery of novel human-use mosquito repellents. Journal of the American Mosquito Control Association, 21, 64-70.

Liddel, J.S. \& Clayton, R. (1982) Long duration fly control on cattle using cypermethrin-impregnated ear tags. Veterinary Record, 110, 502 .

Published 2011. This article is a U.S. Government work and is in the public domain in the USA. Medical and Veterinary Entomology, 26, 131-138 
Marcon, P.C.R.G., Thomas, G.D., Siegfried, B.D. \& Campbell, J.B. (1997) Susceptibility of stable flies (Diptera: Muscidae) from southern Nebraska beef cattle feedlots to selected insecticides and comparison of three bioassay techniques. Journal of Economic Entomology, 90, 293-298.

Paluch, G.E., Coats, J.R., Zhu, J.J. \& Bartholomay, L. (2009) Amyris and Siam-wood Essential Oils: Insect Activity of Sesquiterpenes, ACS Symposium Series, Vol. 1015. American Chemical Society, Washington, DC.

Pavis, C. \& Renou, M. (1990) Study of the shape of the electroantennogram responses in Nezara viridula (L.) (Heteroptera: Pentatomidae). Comptes Rendus de l'Académie des Sciences, Paris, 310, 521-526.

Peterson, C.J. (2001) Insect repellents of natural origin: catnip and osage orange. $\mathrm{PhD}$ dissertation. Iowa State University, Ames, IA.

Rozendaal, J.A. (1997) Vector Control: Methods for Use by Individuals and Communities. World Health Organization, Geneva.

Schreck, C.E., McGovern, T.P. \& Smith, N. (1978) Repellency of selected esters and amides of four alicyclic acids against the stable fly, Stomoxys calcitrans (Diptera: Muscidae). Journal of Medical Entomology, 14, 589-591.

Schultz, G., Simbro, E., Belden, J., Zhu, J. \& Coats, J. (2004) Catnip, Nepeta cataria (Lamiales: Lamiaceae) - a closer look: seasonal occurrence of nepetalactone isomers and comparative repellency of three terpenoids to insects. Environmental Entomology, 33, 1562-1569.

Stork, M.G. (1979) The epidemiological and economic importance of fly infestation of meat and milk producing animals in Europe. Veterinary Record, 105, 341-343.
Sukumar, K., Perich, M.J. \& Boobar, L.R. (1999) Botanical derivatives in mosquito control: a review. Journal of the American Mosquito Control Association, 7, 210-237.

Wang, S. \& Zhang, A. (2008) Facile and efficient synthesis of isolongifolenone. Organic Preparations and Procedures International, 40, 405-410.

Zhang, A., Klun, J.A., Wang, S., Carroll, J.F. \& Debboun, M. (2009) Isolongifolenone: a novel sesquiterpene repellent of ticks. Journal of Medical Entomology, 46, 100-106.

Zhu, J., Zeng, X., Ma, Y. et al. (2006) Comparisons of adult repellency and larvicidal activity of plant essential oils against mosquitoes. Journal of the American Mosquito Control Association, 22, 515-522.

Zhu, J., Zeng, X., Berkebile, D., Du, H.-J., Tong, Y. \& Qian, K. (2009) Efficacy and safety of a novel filth fly repellent. Medical Veterinary Entomology, 23, 209-216.

Zhu, J.J., Dunlap, C.A., Behle, R.W., Berkebile, D. \& Wienhold, B. (2010) Repellency of a wax-based catnip-oil formulation against stable flies. Journal of Agricultural Food and Chemistry, 58, 12320-12326.

Zumpt, F. (1973) The Stomoxyine Biting Flies of the World. Gustav Fisher Verlag, Stuttgart.

Accepted 21 May 2011

First published online 22 July 2011 